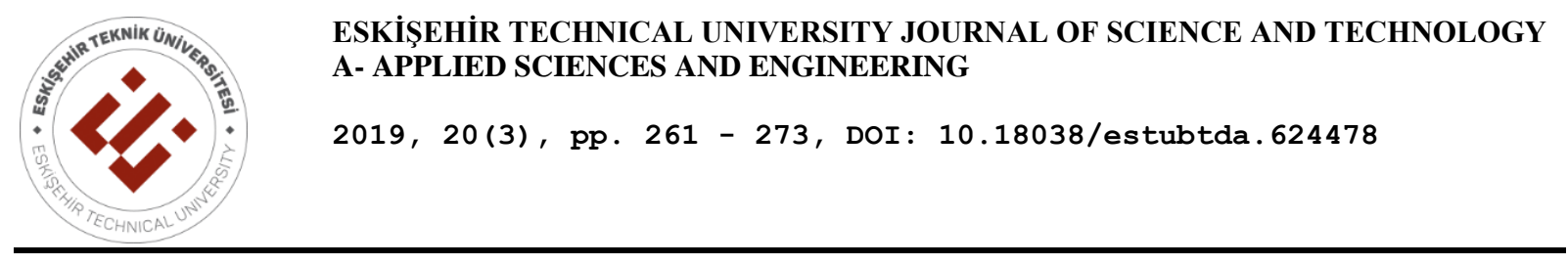

\title{
SUBCRITICAL HYDROTHERMAL CONVERSION OF XYLOSE INTO VALUABLE PRODUCTS IN THE PRESENCE OF DEEP EUTECTIC SOLVENTS
}

\author{
Murat SERT * \\ Chemical Engineering Department, Engineering Faculty, Ege University, Bornova, İzmir, Turkey
}

\begin{abstract}
Hydrothermal conversion in subcritical water is a conversion technique which is attractive method because of its ability to transform wet biomass into valuable chemicals without drying. In this study, the hydrothermal conversion of xylose was carried out in subcritical water in the absence and in the presence of catalysts. Experiments were performed at temperatures of 250, 300 and $350^{\circ} \mathrm{C}$ with a reaction time of $1 \mathrm{~h}$. Deep eutectic solvents (DES) were used as catalysts in the hydrothermal conversion of xylose. The effects of temperature and catalyst addition on the yields of gas and liquid products also on gas and liquid composition were examined. DES 1 consisting of potassium carbonate and ethylene glycol, DES 2 composing choline chloride and urea showed catalytic activity by increasing the liquid yield. The main components were identified as hydroxyacetic acid (glycolic acid), lactic acid, 5-hydroxy methyl furfural, furfural and formic acid. The gas product yield was increased by increasing temperature for all samples. The presence of DESs showed catalytic activity on gas yield and the maximum gas yield was obtained as $31.7 \%$ for DES2
\end{abstract}

Keywords: Xylose, Subcritical water, Deep eutectic solvent

\section{INTRODUCTION}

Lignocellulosic biomass is the most abundant renewable resource and constitutes the cornerstone in the production of sustainable materials, chemicals and energy [1]. Lignocellulosic biomass is essentially consisting of three components: cellulose (35-50 wt\%), hemicellulose, (20-35 wt \%) and lignin (5-30 wt\%) which are responsible for a complex and recalcitrant structure of biomass [2]. Hemicellulose, among major fractions in the biomass besides cellulose and lignin, is a carbohydrate-based fraction composed of hexose and pentose sugars as the monomers such as glucose, mannose, xylose and arabinose. Hemicelluloses could be grouped into four main categories. These are xylans, $\beta$-glucans, xyloglucans, and mannans [3]. Hemicelluloses as polymers, the monomeric sugars have a variety of applications in the chemical, pharmaceutical and alimentary industries [4]. Several techniques, for instance, combustion, pyrolysis, hydrolysis and hydrothermal conversion have been used to convert biomass into value-added chemicals and fuels. Among these techniques, hydrothermal conversion is considered as a promising technique for the conversion of wet biomass to value-added products [5]. The hydrothermal conversion offers several advantages including the use of water as a cheap, environmentally friendly reaction medium with unique properties, and the ability to use wet heterogeneous biomass feedstock without drying or other pretreatment process [6]. There are some studies on the hydrothermal conversion of hemicellulose to understand the conversion mechanism and product identification in literature. The hydrothermal conversion can be carried out in a medium of subcritical or supercritical water. Above the critical point $\left(T_{c}=374^{\circ} \mathrm{C}\right.$ and $\left.P_{c}=22.1 \mathrm{MPa}\right)$, water is called supercritical water. Water retains its liquid feature in subcritical condition or under pressurized conditions between the temperature range of $100-374{ }^{\circ} \mathrm{C}$, it has two unique features. One is the low relative dielectric constant, which is almost the same as those of ambient methanol and acetone. Another feature is the high ion product. There is the possibility that the water can act as an acid or base catalyst without the addition of any further catalyst [7]. Möller and Schröder [5] investigated the uncatalyzed hydrothermal conversion of xylose and xylan as hemicellulose model compounds. The hydrothermal conversion was performed at temperatures of $160-240^{\circ} \mathrm{C}$ and reaction times of 5-240 minutes. They

*Corresponding Author:murat.sert@ege.edu.tr

Received:12.12.2018 Published: 26.09.2019 
found that increasing reaction temperatures and reaction time lead to an increase of the xylose conversion. The maximum furfural yield was obtained as $49 \%$ for uncatalyzed subcritical hydrothermal conversion xylose. When compared to xylose conversion, xylan gave low furfural yields at the same conditions. Noncatalyzed hydrothermal conversion requires high temperature and pressure, so to operate at milder conditions; the suitable catalyst may be used to increase the conversion to value-added chemicals. According to the literature, hydrothermal conversion has been performed using alkali homogeneous catalysts $\left(\mathrm{NaOH}, \mathrm{KOH}, \mathrm{K}_{2} \mathrm{CO}_{3}, \mathrm{Na}_{2} \mathrm{CO}_{3}\right.$, etc) or homogeneneous and heterogeneous transition metals [8]. These homogeneous catalysts have several drawbacks such as; causing to corrosion, producing large amount of waste, lacking of reusability, and difficulty of separation from products. Due to these disadvantages, heterogeneous catalysts were started to be used instead of these environmentally hazardous homogeneous catalysts.

Nowadays, deep eutectic solvents (DES) have increasing interest for the conversion of biomass as well as its constituents. DES is a eutectic mixture generally synthesized by the heating of hydrogen bond donator (HBD) and hydrogen-bond acceptor (HBA) with final melting point significantly lower than each component [9]. Deep eutectic solvents (DESs) are arrangements made from a eutectic mixture of Brønsted-Lewis bases and acids, which has various types of cationic or anionic groups. There are three types of deep eutectic solvents. Different metal halides and the halide anion from the quaternary ammonium salt is the type 1. Type II introduced other metals into formulations and mixing two or more compounds acting as either hydrogen bond donors or hydrogen bond acceptors are used to synthesize type $3[10]$.

DESs are categorized as a type of ionic liquids because of their specific properties [11]. DES shares similar properties with ionic liquids but due to their lower cost, ease to preparation and lower environmental impact when compared to ionic liquids. By considering these advantages, the application areas of DES has increased. Due to their superior properties DESs have gained more concern on its application for biomass treatment [12, 13], conversion of cellulose [14, 15], and also biomass fractionation [16, 17]. Beside these studies, no information about the effect of DES addition in the hydrothermal conversion of hemicellulose into valuable products in subcritical water has been presented to date.

In this study, deep eutectic solvents, which are environmentally friendly materials, were tried to enhance the hydrothermal conversion of xylose. Also, the catalytic effect of two different DESs were clarified for hydrothermal conversion of xylose and the product distribution. The effects of process parameters, DES type and also type of feedstock on the product distribution were highlighted.

\section{MATERIALS AND METHOD}

\subsection{Materials}

Potassium carbonate (PC), ethylene glycol (EG), choline chloride $(\mathrm{ChCl})$ and urea $(\mathrm{U})$ were used in DES synthesis. DES1 containing PC and EG, DES 2 containing $\mathrm{ChCl}$ and $\mathrm{U}$ were used as catalysts for hydrothermal conversion of xylose in subcritical water. All chemicals were purchased from SigmaAldrich.

Preparation of DES 1

The molecular structure of constituents of DES 1 is given in Figure 1. 

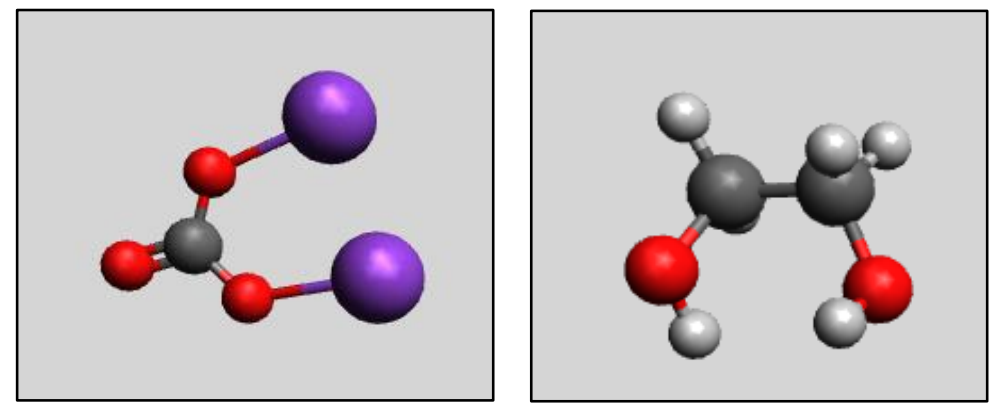

Figure 1. The molecular structure of PC and EG (dark grey: carbon; light grey: hydrogen; red: oxygen; purple: potassium)

To prepare DES1, the specified amounts of potassium carbonate and ethylene glycol with a molar ratio of 1:6 were stirred in a flask and heated until transparent homogenous liquid obtained. Potassium carbonate has a melting point of $1164.15 \mathrm{~K}$ while that of ethylene glycol freezing point is $260.15 \mathrm{~K}$. Mjalli et al. [18] studied on the synthesis and characterization of deep eutectic solvents composing potassium carbonate and ethylene glycol, they found the freezing point of DES composing potassium carbonate and ethylene glycol as $199.85 \mathrm{~K}$. As more ethylene glycol in the composition of the DES results in decreasing the lattice energy and consequently reduction in freezing points.

Preparation of DES 2
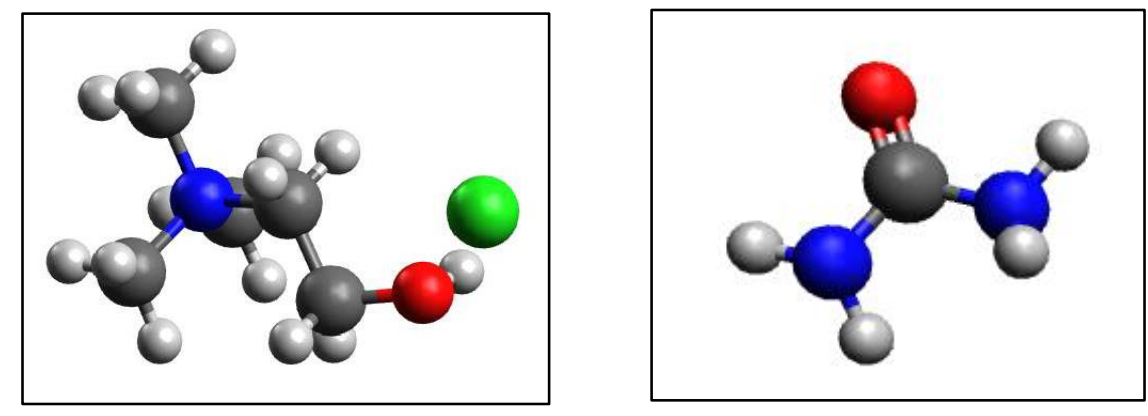

Figure 2. The molecular structure of $\mathrm{ChCl}$ and $\mathrm{U}$ (dark grey: carbon; light grey: hydrogen; red: oxygen; blue: nitrogen and yellow: chlorine)

To prepare DES 2 (Figure 2), the specified amounts of choline chloride and urea with a molar ratio of $1: 2$ were mixed in flask and heated to $80^{\circ} \mathrm{C}$. The stirring process was continued at constant temperature until a transparent eutectic mixture was produced.

The properties of DES 1 and DES 2 are tabulated in Table 1.

Table 1. The physical properties of DESs

\begin{tabular}{lcc}
\hline & DES 1 (PC+EG) [18] & DES 2 $(\mathbf{C h C l + U ) ~ [ 1 9 ] ~}$ \\
\hline Density (g/mL) & 1.33 & 1.095 \\
Viscosity (cP) & 150 & 1300 \\
pH & 12.8 & 10 \\
\hline
\end{tabular}

\section{Properties of xylose}

D-Xylose is a model compound of hemicellulose and was purchased from Alfa Aesar GbbH and Co KG. The molecular structure of D-Xylose is given in Figure 3. 
<smiles>O=CC(O)C(O)C(O)CO</smiles>

\section{D-Xylose}

Figure 3. The molecular structure of D-Xylose

Properties of subcritical water

The physical and chemical properties of subcritical water are given in Table 2.

Table 2. Some physical and chemical properties of subcritical water [20]

\begin{tabular}{lcc}
\hline & Ambient temperature & Subcritical water \\
\hline Temperature $\left({ }^{\circ} \mathbf{C}\right)$ & $0-100$ & $100-374$ \\
Vapor pressure $(\mathbf{M P a})$ & 0.003 & $0.1-22.1$ \\
Density $\left(\mathbf{g} / \mathrm{cm}^{\mathbf{3}}\right)$ & 0.997 & $0.958\left(101^{\circ} \mathrm{C}\right)$ \\
Viscosity $(\boldsymbol{\mu P a s})$ & 884 & $0.692\left(330^{\circ} \mathrm{C}\right)$ \\
Dielectric constant & & $277\left(101^{\circ} \mathrm{C}\right)$ \\
& 78.5 & $50.4\left(371^{\circ} \mathrm{C}\right)$ \\
\hline
\end{tabular}

\subsection{Experimental Procedure}

The hydrothermal conversion experiments were carried out in a stainless steel autoclave. The schematic presentation of reaction system is given in Figure 4. The batch reactor internal volume was $100 \mathrm{~cm}^{3}$. The hydrothermal reaction system was made of a special mixing system and temperature was controlled by temperature controller. The experimental setup also contains gas release pipes, furnace, temperature and pressure controller, autoclave mixing system, gas collection and measurement units with high pressure valves.

$1.2 \mathrm{~g}$ of D-xylose and catalyst; DES 1 or DES $2(5 \mathrm{wt} . \%)$ were fed to the batch autoclave. $15 \mathrm{ml}$ of water was also injected to the reactor. $1.2 \mathrm{~g}$ of biomass and $15 \mathrm{ml}$ of water is the optimum feed amounts with respect to our previous studies for hydrothermal conversion reaction system. The experiments were carried out at temperatures of 250,300 and $350^{\circ} \mathrm{C}$. The reactor was closed tightly and the air inside was purged with nitrogen gas. The system was heated to desired reaction temperature and experiment was continued up to reaction time of $1 \mathrm{~h}$ at the desired reaction temperature. 


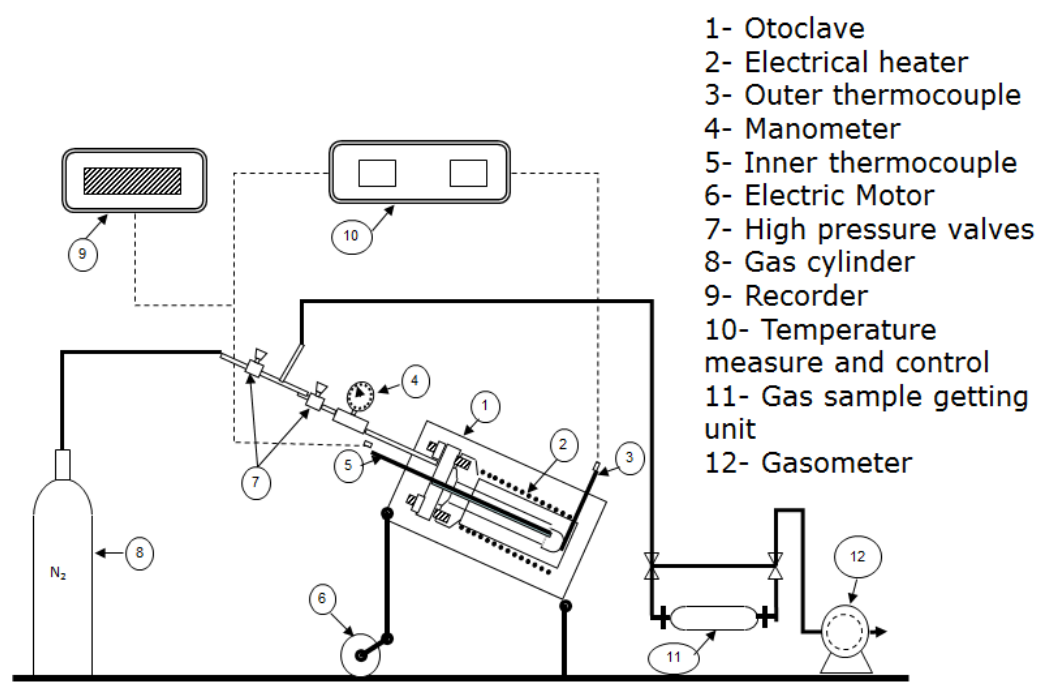

\subsection{Analysis}

Figure 4. Schematic presentation of hydrothermal reaction system

At the end of reaction time, the temperature of the reactor was deceased to room temperature using fans. The amounts of gaseous and liquid products were measured.

Gas analysis; The gaseous products were collected by glass balloon to measure the total gas volume and $50 \mathrm{ml}$ of gas sample was taken by using a gas tight injector. Finally, the composition of gas products were determined by HP7890A Gas chromatograph analyzer. GC Analyzer has two thermal conductivity detectors and one flame ionization detector. It was equipped with P-Plot $\mathrm{Al}_{2} \mathrm{O}_{3} \mathrm{~S}$ column and DB-1 (precolumn). In addition to them, serially connected $0.5 \mathrm{~m}$ long Hayesep Q 80/100 mesh column, $1.8 \mathrm{~m}$ long Hayesep Q 80/100 mesh column, $2.4 \mathrm{~m}$ long Molsieve 5A 60/80 mesh column, $0.9 \mathrm{~m}$ long Hayesep Q 80/100 mesh column, $2.4 \mathrm{~m}$ long Molsieve 5A 60/80 mesh columns were also used in the gas chromatography. As a carries gas Helium was used in the analysis. The temperature program for the analysis was in the following: $60{ }^{\circ} \mathrm{C}$ isothermal for $1 \mathrm{~min}, 20^{\circ} \mathrm{C} \mathrm{min}{ }^{-1}$ to $80{ }^{\circ} \mathrm{C}, 30{ }^{\circ} \mathrm{C} \mathrm{min}-1$ to $120^{\circ} \mathrm{C}$ isothermal for 2.66 min. The calibration of GC was performed with certified standard gas mixture. The compositions of the $\mathrm{C}_{1}-\mathrm{C}_{4}$ hydrocarbons, $\mathrm{H}_{2}, \mathrm{CO}_{2}$, and $\mathrm{CO}$ were determined by gas chromatographic methods.

Liquid analysis; Shimadzu LC-20A series HPLC was used to identify the liquid products that are composed of aldehydes, ketones, carboxylic acids, furfurals and phenols. Inertsil ODS-4 (0.25 m long x $0.0046 \mathrm{~m} \mathrm{ID)} \mathrm{column} \mathrm{was} \mathrm{employed} \mathrm{for} \mathrm{the} \mathrm{analysis.} \mathrm{The} \mathrm{HPLC} \mathrm{system,} \mathrm{consists} \mathrm{of} \mathrm{SPD-20} \mathrm{multi-}$ wavelength ultraviolet detector, LC-20AT gradient pump, CTO-10ASVP chromatography oven and DGU-20AS degassing module. Pure acetonitrile $\left(\mathrm{CH}_{3} \mathrm{CN}\right)$ and water $\left(\mathrm{H}_{2} \mathrm{O}\right)$ with the $\mathrm{pH}$ value of 2.25 were used as mobile phase in the analyzer. The HPLC analysis was performed with the varying volume fraction of the acetonitrile and water mixtures to quantify the carboxylic acids, phenols and furfurals.

According the gas and liquid analysis gas yield, liquid yield and carbon efficiency were determined. Carbon efficiency was defined as the ratio of amount of carbon obtained in liquid and gaseous products to amount of fed carbon in xylose.

\section{RESULTS AND DISCUSSION}

The hydrothermal conversion of xylose in subcritical water was performed in a high pressure-batch autoclave. Experiments were carried out at temperatures of 250,300 and $350^{\circ} \mathrm{C}$. The effects of temperature and catalyst addition were highlighted, and gas and liquid yield and also carbon efficiency were obtained according to the results of analysis. 
The hydrothermal conversion of xylose at 250,300 and $350^{\circ} \mathrm{C}$ without catalyst gave the gas yields of $9.603 \%, 12.519 \%$ and $16.158 \%$, respectively as given in Figure 5 . The gaseous products are composed of methane, ethane, ethylene, propane, butane and hydrogen. The carbon content of these gaseous products were determined with respect to the GC analysis results then the gas yield can be calculated by Equation 1, given below. Temperature increase caused a significant increase in gas yield. As temperature was increased, the gas yield enhanced due to the promotion of free radical reactions such as decarboxylation reaction of the acids to gases [21].

$$
\text { Gas Yield }(\%)=\frac{\sum \text { Carbon content of gaseous products }}{\text { Carbon content of Xylose }} \times 100
$$

DES 1 (PC+EG) was added the system to investigate the effect of catalyst on the hydrothermal conversion of xylose in subcritical water. DES 1 was prepared by mixing of potassium carbonate and ethylene glycol at a specified ratio. Potassium carbonate $\left(\mathrm{K}_{2} \mathrm{CO}_{3}\right)$ known as pearl ash is a white salt is highly soluble in water $(112 \mathrm{~g} / 100 \mathrm{~mL}$ at $293.15 \mathrm{~K})$ forming a strong alkaline solution. Ethylene glycol has been utilized as a hydrogen bond donor, and combination with potassium carbonate may be good candidate for catalytic applications [18]. DES 1 increased the gas yield at all temperatures and the maximum gas yield was obtained as $21.32 \%$ at $350^{\circ} \mathrm{C}$ in the presence of DES 1 .

DES $2(\mathrm{ChCl}+\mathrm{U})$ was used to accelerate the xylose conversion. Temperature is the key parameter for biomass conversion in thermal processes. Like other samples, gas yield was increased with respect to temperature. DES 2 showed positive catalytic effect on the formation of gas products when compared to the gas products of raw xylose. The maximum gas yield was obtained $31.7 \%$ at $350^{\circ} \mathrm{C}$ for DES 2 .

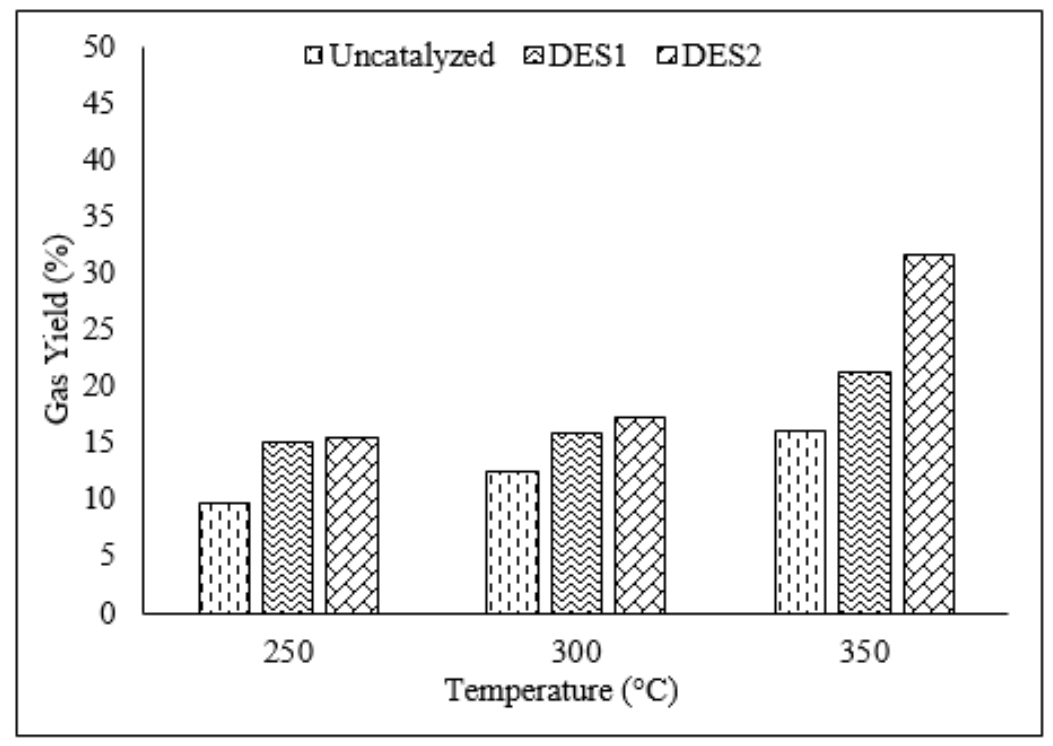

Figure 5. The gas yields for the hydrothermal conversion of xylose in subcritical water

The liquid product yield is defined as the ratio of summation of carbon content of water soluble valuable products after xylose hydrothermal conversion reaction to carbon content of feed xylose in this study. After the HPLC analysis, the liquid products were identified and these chemicals are given in Figure 8. Carbon contents of all measured liquids product were determined. The liquid product yields can be calculated by Equation 2 .

$$
\text { Liquid Yield }(\%)=\frac{\sum \text { Carbon content in liquid products }}{\text { Carbon content of Xylose }} \times 100
$$


Figure 6 represents the liquid yield for uncatalytic and catalytic hydrothermal conversion of xylose. The liquid yields were determined as $21.01 \%, 17.31 \%$ and $11.55 \%$ at temperatures of 250,300 and $350^{\circ} \mathrm{C}$ in the absence of catalyst. Temperature increase caused increase in gas yield and decrease in water soluble conversion product yield as expected. The catalyst addition favored the formation of liquid products. The maximum liquid yield was obtained at $250^{\circ} \mathrm{C}$ for uncatalytic and catalytic hydrothermal conversion of xylose in subcritical water. In the presence of DES 1 (PC + EG), the liquid yield increased from $21.01 \%$ to $36.52 \%$, from $17.31 \%$ to $27.99 \%$, from $11.55 \%$ to $16.24 \%$ at temperatures of 250,300 and $350^{\circ} \mathrm{C}$. DES 1 showed catalytic activity due to its high solvability capacity. In the presence of DES $2(\mathrm{ChCl}+\mathrm{U})$, the liquid yields increased to $47.35 \%, 40.01 \%$ and $17.24 \%$ at temperatures of 250,300 and $350^{\circ} \mathrm{C}$, respectively. The highest liquid yield was achieved as $47.35 \%$ in the presence of DES 2 $(\mathrm{ChCl}+\mathrm{U})$ which act as both a solvent and a catalyst.

Abbas and Binder [22] reported the properties of deep eutectic solvent containing choline chloride and urea, the decomposition temperature was examined using thermogravimetric analysis. TGA curves showed that decomposition of DES 2 started at $300^{\circ} \mathrm{C}$, the high weight loss was achieved above $300^{\circ} \mathrm{C}$. So, the catalytic effect of DES 2 was clear at $250^{\circ} \mathrm{C}$ when compared to higher temperatures, especially $350^{\circ} \mathrm{C}$. At $350^{\circ} \mathrm{C}$, there was a little effect on the liquid yield due to the decomposition of DES 2 .

The amounts of components in gas product were listed in Table 3, temperature increase and catalyst addition increased the gas formation, especially $\mathrm{CO}_{2}$. In hydrothermal conversion of xylose in the presence of DES 2, the amount of $\mathrm{CO}_{2}$ was increased from 217.2 to $480.8 \mathrm{~g} / \mathrm{kg}$ xylose at $350^{\circ} \mathrm{C}$. This result was lined with liquid yield results.

Table 3. The gas amounts ( $\mathrm{g} / \mathrm{kg}$ Xylose) for the hydrothermal conversion of xylose in subcritical water at different temperatures

\begin{tabular}{cccccccccc}
\hline & \multicolumn{3}{c}{ Uncatalyzed } & & DES1 & \multicolumn{3}{c}{ DES2 } \\
\hline & $250^{\circ} \mathrm{C}$ & $300^{\circ} \mathrm{C}$ & $350^{\circ} \mathrm{C}$ & $250^{\circ} \mathrm{C}$ & $300^{\circ} \mathrm{C}$ & $350^{\circ} \mathrm{C}$ & $250^{\circ} \mathrm{C}$ & $300^{\circ} \mathrm{C}$ & $350^{\circ} \mathrm{C}$ \\
$\mathbf{C}_{\mathbf{1}}-\mathbf{C}_{\mathbf{4}}$ & 0.1 & 0.9 & 6.7 & 0.2 & 1.0 & 4.4 & 0.1 & 1.4 & 44.4 \\
$\mathbf{C O}_{2}$ & 140.6 & 180.7 & 217.2 & 219.3 & 230.2 & 299.8 & 219.7 & 248.2 & 480.8 \\
$\mathbf{H}_{2}$ & 0.4 & 1.1 & 1.4 & 0.8 & 1.0 & 4.7 & 0.8 & 1.9 & 12.9 \\
\hline
\end{tabular}

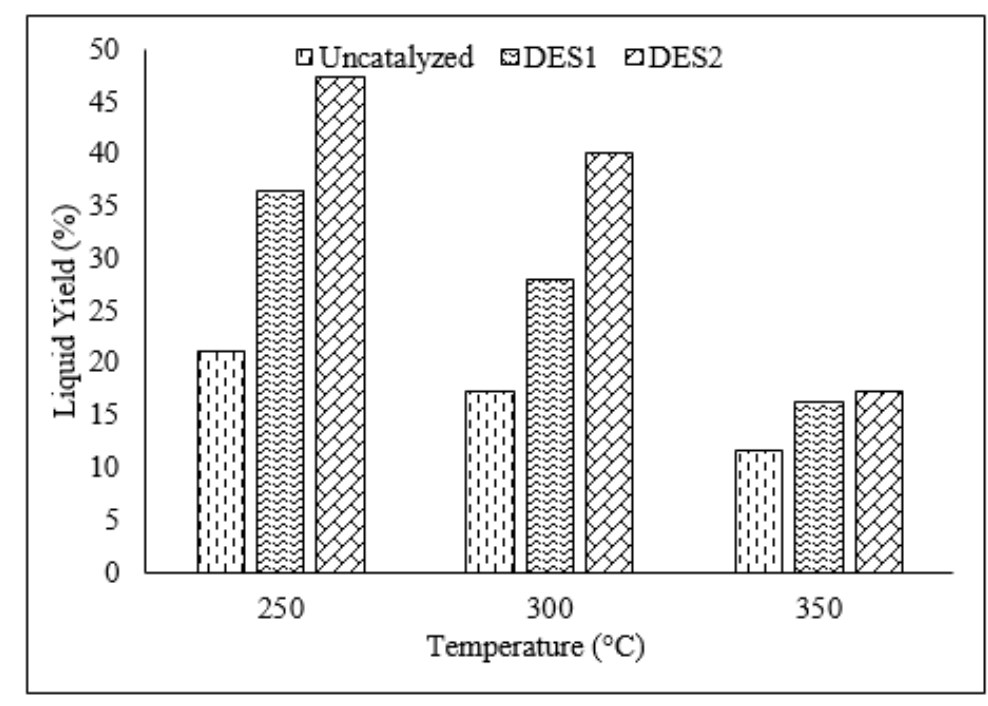

Figure 6. The liquid yields for the hydrothermal conversion of xylose in subcritical water

$\mathrm{C}$ efficiency can be defined as the ratio of the total amount of $\mathrm{C}$ in gaseous and liquid products after conversion of xlyose to $\mathrm{C}$ in fed xylose. $\mathrm{C}$ efficiency values were given in Figure 7, the highest $\mathrm{C}$ efficiency values were achieved at $250^{\circ} \mathrm{C}$ for uncatalytic and catalytic runs. For the uncatalytic 
hydrothermal conversion, carbon efficiencies were achieved as $30.62 \%, 29.83 \%$ and $27.7 \%$ at temperatures of 250,300 and $350^{\circ} \mathrm{C}$, respectively. There was a slight decrease in carbon efficiency due to temperature increase. The reason for the decrease in $\mathrm{C}$ efficiency may come from the increase in the formation of humins and tar with respect to temperature. Gallo and Trapp stated that hydroxyl groups of HMF suppress the rehydration while decomposion of biomass and causes the formation of humin that is undesirable side products [23].

Both DES 1 and DES 2 increased to carbon efficiency. At $250^{\circ} \mathrm{C}$, DES 1 increased the carbon efficiency from $30.62 \%$ to $51.51 \%$ and DES 2 enhanced the carbon efficiency to $62.91 \%$ at $250^{\circ} \mathrm{C}$. The maximum carbon efficiency of $62.91 \%$ was achieved at $250^{\circ} \mathrm{C}$ in the presence of DES 2 . At $350^{\circ} \mathrm{C}, \mathrm{C}$ efficiency decreased from $62.91 \%$ to $48.94 \%$ due to polymerization of products, humin and tar formation. Humin and other side products are undesired chemicals in the conversion of biomass [23, 24]. The higher temperatures favored the further reactions and high molecular weight products may be produced, and low $\mathrm{C}$ efficiencies were obtained.

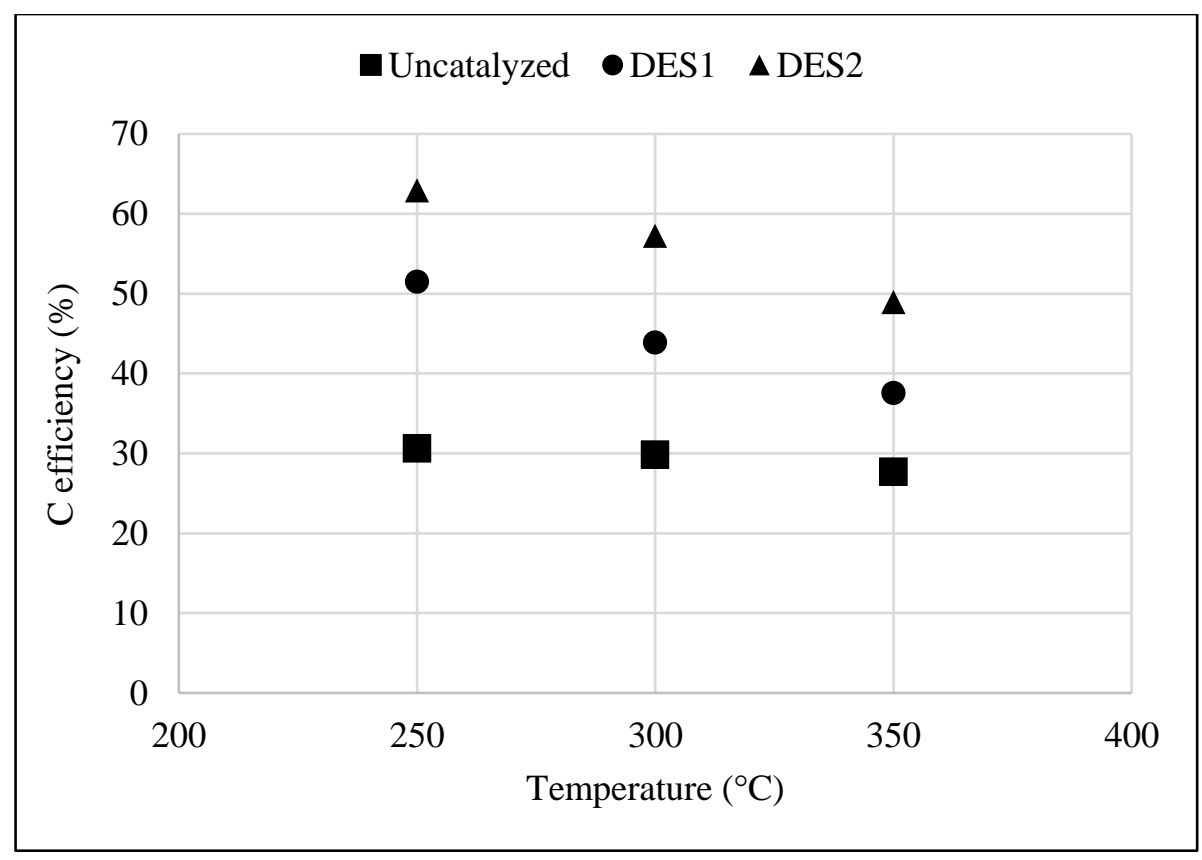

Figure 7. The effects of temperature and catalyst on C efficiency

Figure 8 illustrates the amounts of liquid products for uncatalyzed hydrothermal conversion of xylose in subcritical water. The production of valuable compounds from xylose involves several complex reactions and several intermediate products. In subcritical water medium, xylose is converted into 5$\mathrm{HMF}$ and furfural. The decomposition of 5-HMF produces furfural. The amounts of furfural, 5-HMF were obtained around 10 and $31.5 \mathrm{~g} / \mathrm{kg}$ biomass at $250^{\circ} \mathrm{C}$. The furfural yield in batch processes has reported as low values due to the occurrence of undesired parallel reactions leading to formation of humins [2]. The proposed mechanism of xylose conversion in subcritical water was given in Figure 9. 
Sert / Eskişehir Technical Univ. J. of Sci. and Tech. A-Appl. Sci. and Eng. 20 (3) - 2019

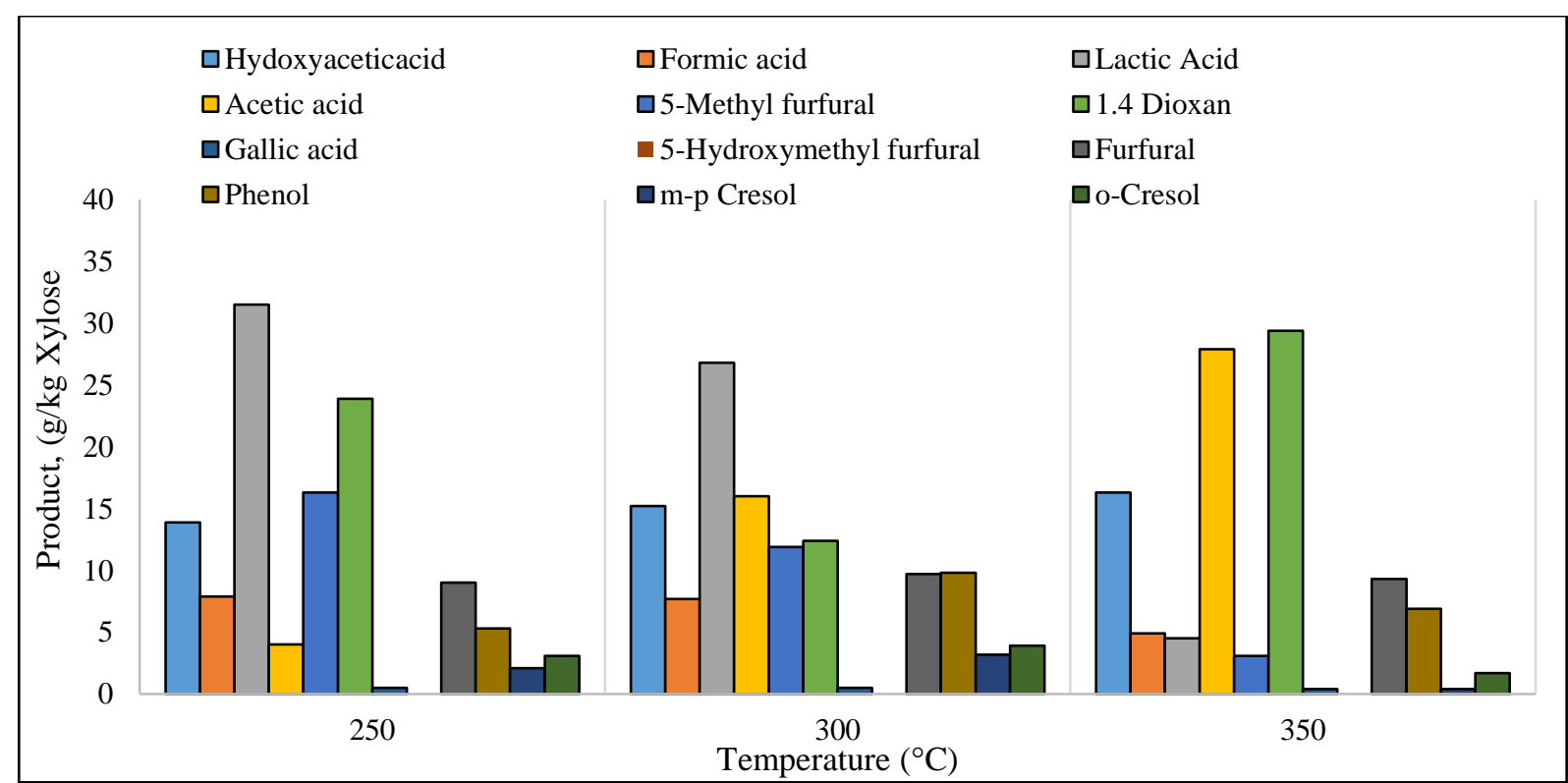

Figure 8. The amounts of liquid products for uncatalyzed hydrothermal conversion of xylose in subcritical water

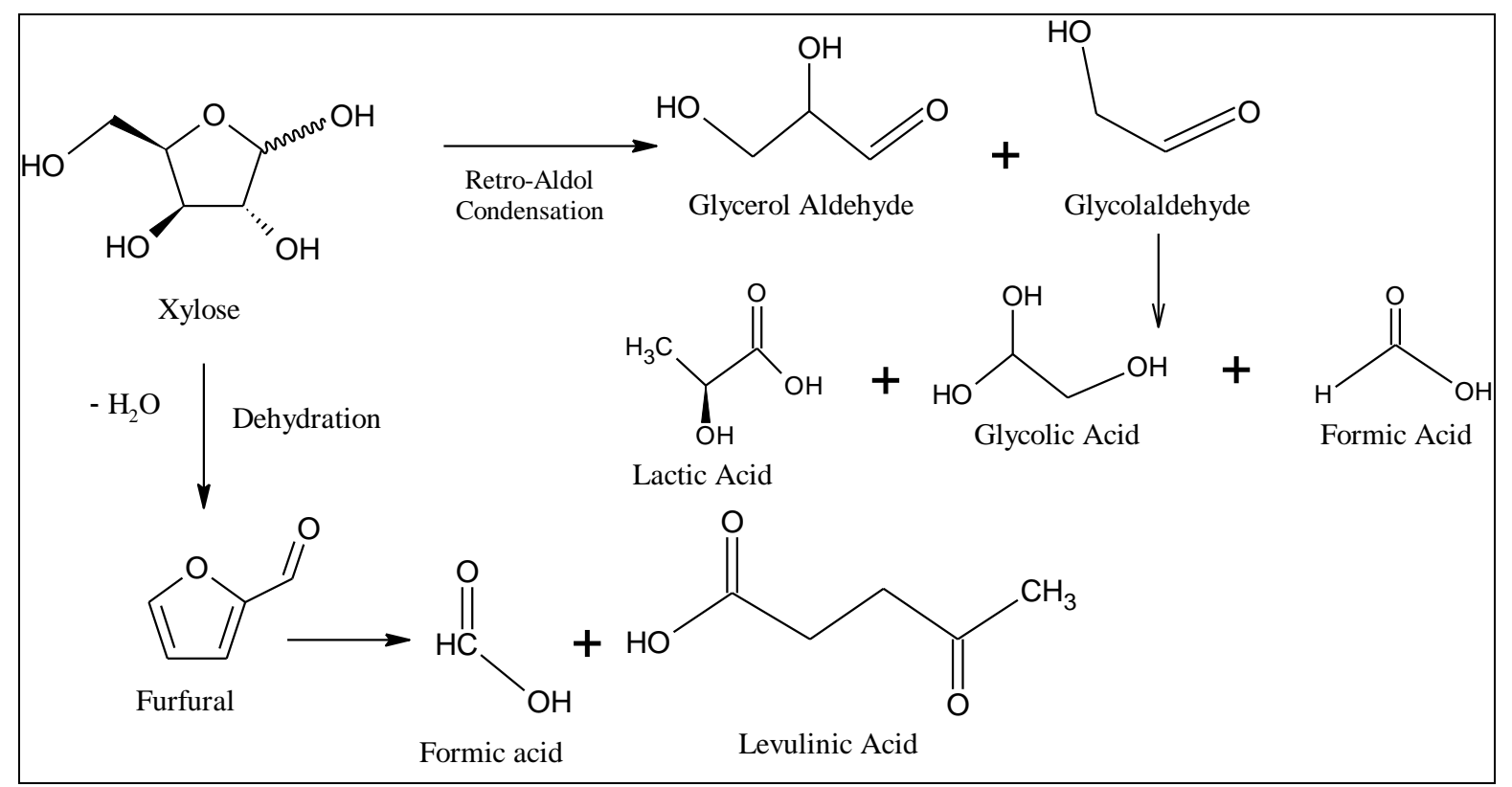

Figure 9. The mechanism of xylose conversion [25]

In literature, there are several approaches to improve yields of value-added compounds such as use of several acidic or basic catalysts, homogeneous or heterogeneous systems and monophasic/biphasic reaction systems. In this study, two different deep eutectic solvents were used to achieve improvements in the yields of furfural and 5-HMF. Figure 10 shows the effect of DES 1 on the amounts of compounds in liquid composition. 
Sert / Eskişehir Technical Univ. J. of Sci. and Tech. A - Appl. Sci. and Eng. 20 (3) - 2019

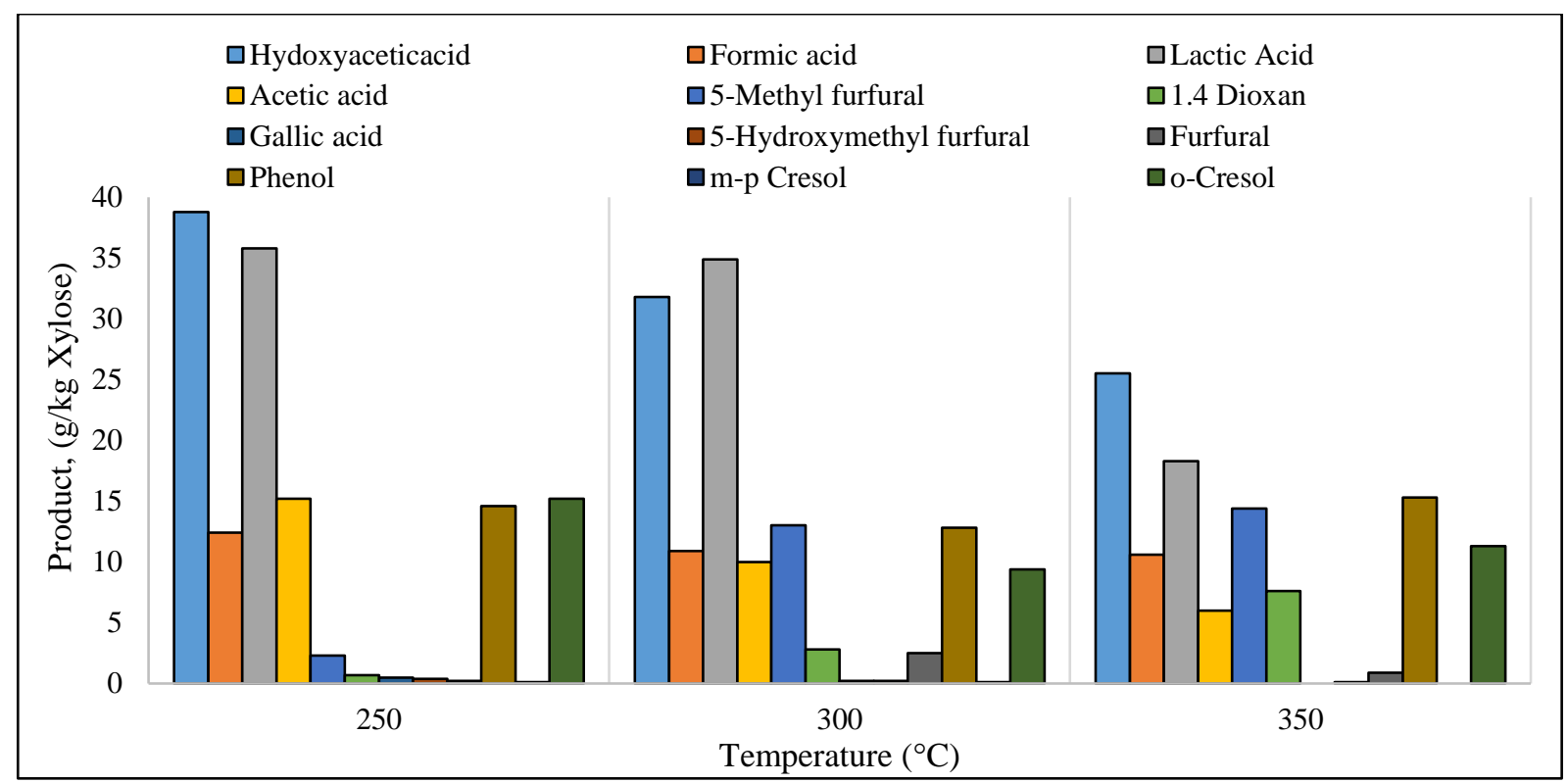

Figure 10. The amounts of liquid products for hydrothermal conversion of xylose in subcritical water catalyzed by DES 1

Xylose conversion may proceed in two ways; furfural, 5-HMF, levulinic acid and formic acid can be produced by dehydration, glycolic acid, lactic acid and formic acid are produced through retro aldol condensation reactions. DES 1 is a highly basic catalyst, the basic medium promotes the retro aldol condensation reactions. DES 1 provides the basic medium for the hydrothermal conversion of xylose. The use of DES 1 (PC+EG) increased the amount of hydroxyacetic acid (glycolic acid) from 13.9 to $38.8 \mathrm{~g} / \mathrm{kg}$ biomass because of the basic nature of DES 1 . Also formation of formic acid enhanced in the presence of DES 1 as catalyst due to the acidic nature of subcritical water. At subcritical condition, the ion products $\left(\mathrm{H}_{3} \mathrm{O}^{+}\right.$and $\left.\mathrm{OH}^{-}\right)$in water will make the water acidic and at this condition the water become a good solvent for converting xylose to other products [26].

The performance of DES 2 in xylose conversion under different reaction temperatures is summarized in Figure 11. DES $2(\mathrm{ChCl}+\mathrm{U})$ increased the liquid yield and the composition of some products. The amount of hydroxyacetic acid was increased from 13.9 to $17.7 \mathrm{~g} / \mathrm{kg}$ xylose in the presence of DES 2 . The maximum amount of hydroxyacetic acid was found as $38.8 \mathrm{~g} / \mathrm{kg}$ xylose at $250^{\circ} \mathrm{C}$ for hydrothermal conversion catalyzed by DES 1 . The main components of liquid product were obtained as hydroxyacetic acid, formic acid and lactic acid for the hydrothermal conversion of xylose in subcritical water. DES 2 $(\mathrm{ChCl}+\mathrm{U})$ showed slightly less basic character when compared to DES 1 . The reaction pathway proceeds to retro aldol reaction routes [27]. 
Sert / Eskişehir Technical Univ. J. of Sci. and Tech. A-Appl. Sci. and Eng. 20 (3) - 2019

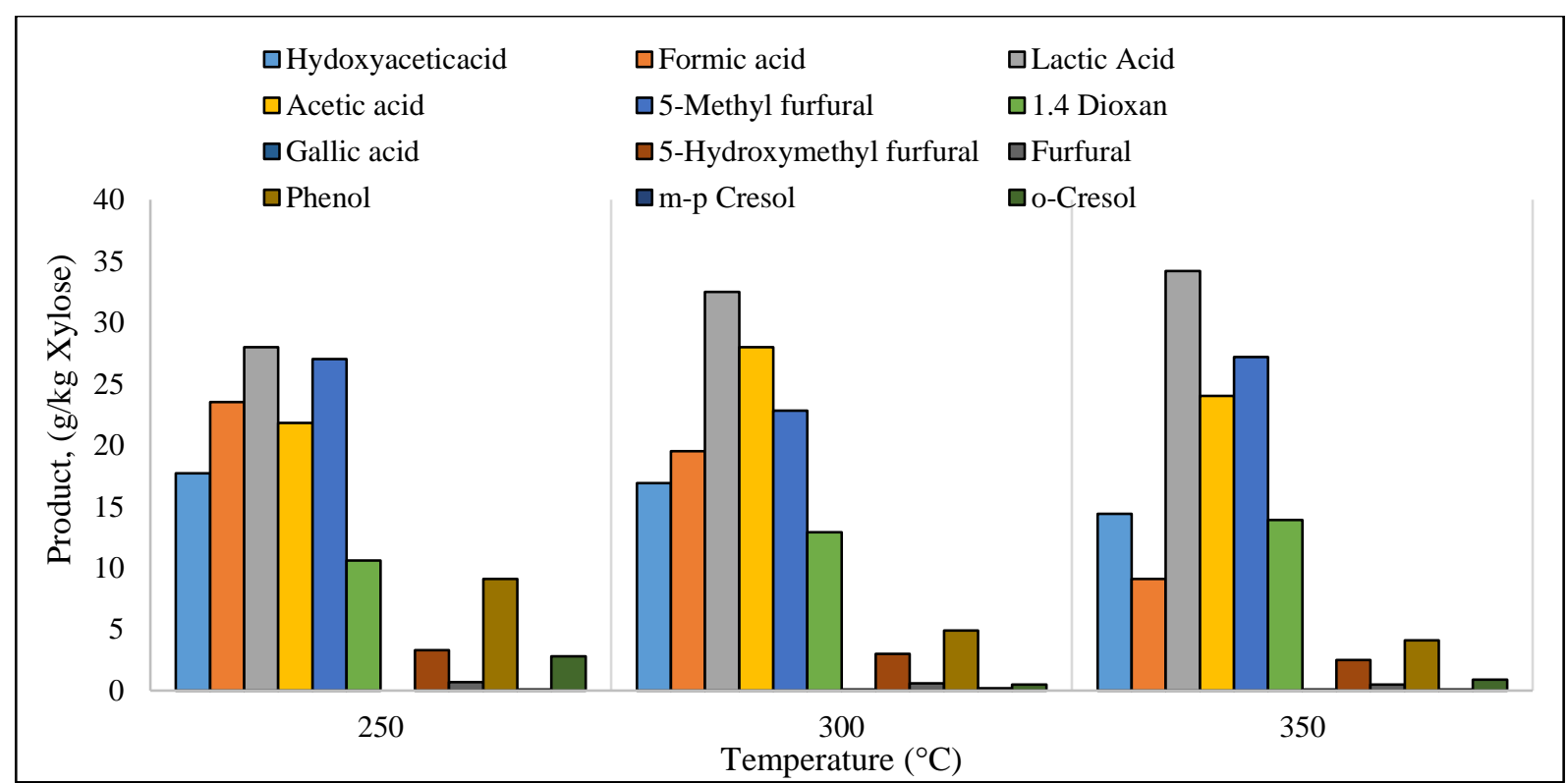

Figure 11. The amounts of liquid products for hydrothermal conversion of xylose in subcritical water catalyzed by DES 2

This study highlights the use of DES as a catalyst and solvent for hydrothermal conversion of xylose. The studies on the application of DES in hydrothermal conversion of biomass constituents are limited and this study could help to understand the effect of DES addition for the hydrothermal conversion of xylose.

\section{CONCLUSION}

Hydrothermal conversion of Xylose as a model compound of hemicellulose to valuable products was studied under subcritical water condition in the absence/presence of deep eutectic solvent (DES). Two types of DES were used in this study. DES 1 was synthesized by potassium carbonate and ethylene glycol, DES 2 was synthesized by choline chloride and urea. The reaction temperatures were 250, 300 and $350{ }^{\circ} \mathrm{C}$. As expected in hydrothermal conversion, the gas yield was increased with increasing temperature for all xylose samples. The highest yield was achieved with DES 2 at $350{ }^{\circ} \mathrm{C}$. And the yield of the liquid products which were produced after hydrothermal conversion decreased in contrast to gas yield. The highest liquid product yield (47.3\%) was obtained in the presence of DES 2 at $250{ }^{\circ} \mathrm{C}$. The carbon efficiencies were calculated and found as 30.6\%, 51.5\% and $62.9 \%$ for Uncatalyzed, DES 1 and Des 2 samples respectively. Regarding the results, DES 1 and DES 2 showed positive catalytic effect on conversion of xylose. In addition to this, water soluble organic product formation increased in the presence of DES.

\section{ACKNOWLEDGEMENTS}

I gratefully appreciate the financial support of Ege University Scientific Research Project (Project No: 18 MÜH 022).

\section{REFERENCES}

[1] Martínez-Abad A, Giummarella N, Lawoko M, Vilaplana F. Differences in extractability under subcritical water reveal interconnected hemicellulose and lignin recalcitrance in birch hardwoods. Green Chem. 2018; 20: 2534-2546. 
Sert / Eskişehir Technical Univ. J. of Sci. and Tech. A-Appl. Sci. and Eng. 20 (3) - 2019

[2] C Morais AR, Matuchaki MD, Andreaus J, Bogel-Lukasik R. A green and efficient approach to selective conversion of xylose and biomass hemicellulose into furfural in aqueous media using high-pressure $\mathrm{CO}_{2}$ as a sustainable catalyst. Green Chem. 2016; 18: 2985-2994.

[3] Soleimani M, Tabil LG, Panigrahi S. A kinetic study of xylose recovery from a hemicellulose-rich biomass for xylitol fermentative production. https://doi.org/10.1080/00986445.2018.1478294

[4] Fernández MA, Rissanen J, Nebreda AP, Xu C, Willför S, García Serna J, Salmi T, Grénman H. Hemicelluloses from stone pine, holm oak, and Norway spruce with subcritical water extraction-comparative study with characterization and kinetics. The Journal of Supercritical Fluids 2018; 133: 647-657.

[5] Möller M, Schröder U. Hydrothermal production of furfural from xylose and xylan as model compounds for hemicelluloses. The Royal Society of Chemistry 2013; 3: 22253-22260.

[6] Pavlovic I, Knez Z, Škerget M. SubcriticalWater-a Perspective Reaction Media for Biomass Processing to Chemicals: Study on Cellulose Conversion as a Model for Biomass. Chem. Biochem. Eng. 2013; 27-1: 73-82.

[7] Chen X, Liu X, Xu F, Bai X. Degradation kinetics of xylose and arabinose in subcritical water in unitary and binary system. Advanced Materials Research 2012; 450-451: 710-714.

[8] Salimi M, Tavasoli A, Balou S, Hashemi H, Kohansal K. Influence of promoted bimetallic Nibased catalysts and Micro/Mesopores carbonaceous supports for biomass hydrothermal conversion to $\mathrm{H}_{2}$-rich gas. Applied Catalysis B: Environmental 2018; 239: 383-397.

[9] Liang X, Fu Y, Chang J. Effective separation, recovery and recycling of deep eutectic solvent after biomass fractionation with membrane-based methodology. Separation and Purification Technology 2019; 210: 409-416.

[10] Jiang Z, Yuan J, Wang P, Fan X, Xu J, Wang Q, Zhang L. Dissolution and regeneration of wool keratin in the deep eutectic solvent of choline chloride-urea. Int. Journal of Biological Macromolecules 2018; 119: 423-430.

[11] Saravana PS, Cho YN, Woo HC, Chun BS. Green and efficient extraction of polysaccharides from brown seaweed by adding deep eutectic solvent in subcritical water hydrolysis. Journal of Cleaner Production 2018; 198: 1474-1484.

[12] Chen Z, Reznicek WD, Wan C. Deep eutectic solvent pretreatment enabling full utilization of switchgrass", Bioresource Technology 2018; 263: 40-48.

[13] Satlewal A, Agrawal R, Bhagia S, Sangoro J, Ragauskas A J. Natural deep eutectic solvents for lignocellulosic biomass pretreatment: Recent developments, challenges and novel opportunities. Biotechnology Advances 2018; 36: 2032-2050.

[14] Sert M, Arslanoglu A, Ballice L. Conversion of sunflower stalk based cellulose to the valuable products using choline chloride based deep eutectic solvents. Renewable Energy 2018; 118: 9931000 .

[15] Gawade AB, Yadav GD. Microwave assisted synthesis of 5-ethoxymethylfurfural in one pot from D-fructose by using deep eutectic solvent as catalyst under mild condition. Biomass and Bioenergy 2018; 117: 38-43. 
[16] Chen Z, Wan C. Ultrafast fractionation of lignocellulosic biomass by microwave-assisted deep eutectic solvent pretreatment. Bioresource Technology 2018; 250: 532-537.

[17] Li AL, Hou XD, Lin KP, Zhang X, Fu MH. Rice straw pretreatment using deep eutectic solvents with different constituents molar ratios: Biomass fractionation, polysaccharides enzymatic digestion and solvent reuse. Journal of Bioscience and Bioengineering 2018; 126-3: 346-354.

[18] Mjalli FS, Naser J, Jibril B, Al-Hatmi SS, Gano ZS. Ionic liquids analogues based on potassium carbonate", Thermochimica Acta 2014; 575: 135- 143.

[19] Mjalli FS, Ahmed OU. Characteristics and intermolecular interaction of eutectic binary mixtures: Reline and Glyceline. Korean J. Chem. Eng. 2016; 33(1): 337-343.

[20] Möller M, Nilges P, Harnisch F, Schröder U. Subcritical Water as Reaction Environment: Fundamentals of Hydrothermal Biomass Transformation. ChemSusChem. 2011; 4: 566 - 579.

[21] Harry I, Ibrahim H, Thring R, Idem R. Catalytic subcritical water liquefaction of flax straw for high yield of furfural. Biomass and Bioenergy 2014; 71: 381-393.

[22] Abbas Q, Binder L. Synthesis and characterization of choline chloride based binary mixtures. ECS Transactions 2010; 33-7: 49-59.

[23] Gallo J.M.R., Trappb M.A. The Chemical Conversion of Biomass-Derived Saccharides: an Overview: J. Braz. Chem. Soc. 2017; 28-9: 1586-1607.

[24] Kumar K, Parveen F, Patra T, Upadhyayula S. Hydrothermal conversion of glucose to levulinic acid using multifunctional ionic liquids: effects of metal ion co-catalysts on the product yield. New J. Chem. 2018; 42: 228-236.

[25] DelbecqF, Wang Y, Muralidhara A, El Ouardi K, Marlair G, Len C. Hydrolysis of Hemicellulose and Derivatives-A Review of Recent Advances in the Production of Furfural. Frontiers in Chemistry 2018; 6: 146-175.

[26] Hartono CD, Marlie KJ, Putro JN. Levulinic acid from corncob by subcritical water process. Int. J. Ind. Chem. 2016; 7: 401-409.

[27] Aida TM, Shiraishi N, Kubo M, Watanabe M, Smith RL Jr. Reaction kinetics of d-xylose in suband supercritical water. J. of Supercritical Fluids, 2010; 55: 208-216. 